\title{
Simulation of development of individual heavy industry sectors ${ }^{*}$
}

\author{
Evgeniy V. Kislitsyn
}

E-mail:kev@usue.ru

\author{
Victor V. Gorodnichev \\ E-mail: helltoaster@yandex.ru \\ Ural State University of Economics \\ Address: 62, 8 Marta Street, Yekaterinburg 620144, Russia
}

\begin{abstract}
Nowadays, in the context of the coronavirus crisis, the issue of ensuring the sustainable development of heavy industries is acute. However, theoretical and analytical researches alone are not sufficient for this, and economic science needs to develop fundamentally new approaches to the study of the development of industrial sectors. This article is devoted to the creation and testing of a simulation model for the development of individual sectors of the economy. The object of research is the metallurgical industry, as well as related ore mining, mechanical engineering and production of finished metal products. The theoretical basis of the research is a systematic approach that combines the theory of industry markets, economic growth, industrial economics, system dynamics and mathematical economics. The main research methods used are system analysis, statistical analysis to identify trends in changes in the main economic indicators, econometric modeling to build production functions, as well as mathematical modeling of macroeconomic systems. As a result, a simulation model developed in system dynamics notation is proposed, which makes it possible to evaluate the development of individual industries taking into account various changes. This model is built on the basis of the three-sector model of the national economy, where separate adjacent industries connected by dynamic feedback loops are identified as structural elements. The paper details the structure of the simulation model based on first-order dynamic equations, balance equations and nonlinear production functions. The simulation model allowed us to predict a number of scenarios for the development of metallurgical industries, taking into account changes in the labor force and investment in fixed assets. The results of the work can be used for forming proposals on industrial policy, monitoring the condition and efficiency of individual industries.
\end{abstract}

Key words: simulation; system dynamics; industry; metallurgy; three-sector model of the economy; production function; mathematical model.

\footnotetext{
* The article is published with the support of the HSE University Partnership Programme
} 
Citation: Kislitsyn E.V., Gorodnichev V.V. (2021) Simulation of development of individual heavy industry sectors. Business Informatics, vol. 15, no 1, pp. 59-77. DOI: 10.17323/2587-814X.2021.1.59.77

\section{Introduction}

$\mathrm{S}$ ustainable development of heavy industries remains a top priority for the national economy. Mechanisms for ensuring such development form the basis of the industrial policy of the Russian Federation, individual national projects and programs [1]. Therefore, the task of finding new ways, methods and tools to ensure and support the sustainable development of heavy industry sectors is most relevant. In modern Russian and foreign studies, both classical economic $[2,3]$ and new interdisciplinary approaches $[4,5]$ are used to deal with these tasks. However, it is almost impossible to develop such tools without using modern mathematical tools and computing systems.

For the most part, analytical studies in this area boil down to the analysis of the current situation in individual industries $[6,7]$, regions [8-10] and the economy as a whole [11], as well as to the construction of econometric models and interpretation of the dependencies found for further adjustments to industrial policy. However, such models practically do not take into account, firstly, the nonlinear behavior of economic systems and, secondly, the presence of causal relationships between individual indicators of these systems. The use of mathematical and simulation modeling in the research of industries is encountered in modern studies more and more often, however, the models proposed by the authors are not always theoretically substantiated and empirically tested.

In this study, an attempt is made to use the ideas of mathematical economics and, in particular, the modeling of macroeconomic dynamic systems in combination with simu- lation modeling to study the development of sectoral economic systems. This synthesis is possible through the use of causal and flow simulation notations. A feature of the proposed approach is the use of methods of system dynamics first proposed in the works of J. Forrester [12, 13] and D. Meadows [14, 15], and subsequently developed in the works of V.N. Sidorenko [16], A.S. Akopov [17-19] and other researchers. Dynamic models of macroeconomic systems, as a rule, are based on differential equations of the first order, which can be represented in the notation of system dynamics using flow stratification.

The aim of this study is to develop a simulation model for the development of individual industries using the example of metallurgy and related industries (mining of metal ores, mechanical engineering, production of finished metal products), using the ideas of a three-sector model of the economy and system dynamics. In accordance with the purpose of the study, the following tasks were set and solved:

1) to analyze the available research in the field of simulation modeling of economic systems;

2) to modify the three-sector mathematical model of the economy in relation to individual industries;

3) to create the structure of a simulation model for the development of individual industries, to determine the main storage devices, flows, variables and parameters of the model;

4) to test the simulation model so created and simulate six different scenarios for the development of the metallurgical and related industries. 


\section{Theoretical background for study of mathematical and simulation models of industries}

For studying long-term trends and growth factors, as well as for evaluating the consequences of various macroeconomic decisions, non-linear small-sector models are used. In such models, the structure of the economy is presented in the form of sectors, each of which produces some aggregated product. The basis here is the one-sector Solow model [20], in which the economic system is considered as a kind of unstructured apparatus that produces a single universal product. This model reflects the process of reproduction and allows us to analyze the relationship between consumption and accumulation.

Further development of the one-sector Solow model led to the two-sector [21] and three-sector models [22]. The appearance of such models allows us not only to analyze the growth of the economy as a whole, but also to focus attention on its individual sectors. However, the development of these ideas mainly lies in the study of macroeconomic systems. At the same time, no less important is the problem of the development of individual sectors, first of all, industry. The ideas presented in the three-sectoral model [22, 23], according to the author, can be used to study economic growth not of the sectors of the economy as a whole, but of its individual branches, most closely related to each other. The only assumption that must be observed when modifying this model is the need to represent industries from three sectors of the economy - material, fund-creating, and consumer.

The mathematical tools presented in the three-sector model of the economy are a set of differential equations, balance equations, and nonlinear production functions. The analytical solution of the three-sector model of the economy for balanced economic growth is described in detail in $[23,24]$. Within the framework of this study, it is proposed to use a fundamentally different approach - simulation modeling.

Simulation modeling is an experimental method for studying a real or projected system based on its simulation model, which combines the features of an experimental approach with specific conditions for using computer technology [25]. According to the accepted classification, there are three approaches to creating simulation models: discrete-event modeling, system dynamics, and agent-based modeling [26].

Discrete-event simulation is mainly used to analyze business processes and production systems in enterprises, where logic can be described as a sequence of specific actions. For example, in [27], simulation is used to assess the risks of industrial enterprises. This simulation model is a process (discrete-event) model of the production process, on which statistical tests were carried out and the variation in the value of the profitability indicator was investigated depending on various input factors.

When describing meso- and macroeconomic systems, it is rational to use two other approaches - system dynamics and agentbased modeling. At the same time, agent-based modeling is used in the case when in the system, in an explicit form, separate subjects are distinguished, with such characteristics as possessing discreteness, sociality, activity, autonomy and flexible behavior [28]. In particular, a stochastic model of economic growth with four types of agents: production (firm), consumer, foreign markets and the state is presented in the work of A.V. Vorontsovsky [29]. This study examines a single-product model with domestic and foreign producers which uses the classic Cobb-Douglas production function and considers production conditions, the consumer's problem and relationships for the state as the main governing elements. The work of D.N. Shultz and I.N. Yakupova [30] is devoted to solving the classical problem of agent-based modeling - assessing how the behavior of each of the agents affects the development of 
the system as a whole. In particular, this work examines the influence of microstructures on the properties of the economy as a whole.

System dynamics models make it possible to identify cause-and-effect relationships in the economic system. They usually consist of accumulators (levels), which are accumulations in feedback circuits, flows that regulate the rate of change of accumulators, auxiliary variables and cycles (feedback loops).

System dynamics models are based on differential equations, which justifies their use when trying to breathe new life into classical dynamic (continuous) economic models. N.V. Yandybaeva and V.A. Kushnikov [31] developed a complex system-dynamic model for predicting the indicators of the economic security of the Russian Federation. This model contains 11 systemic levels, including the growth rate of consumer prices, the unemployment rate, etc., as well as four functional dependencies and several dozen auxiliary variables.

E.I. Piskun [32] used system dynamics to build a model of the mutual influence of variables for assessing the effectiveness of the strategy of innovative development of production and economic systems, using several scenarios for the development of the system for the analysis. The model calculates indicators such as the average chain growth rate, as well as the average growth rate of levels of innovation intensity, efficiency of investment activities, innovation potential and development of production and economic systems.

Particular attention is paid to studies of the interaction between economic growth and resource consumption, which can also be expressed using differential mathematical models. Thus, in [33], a model in the notation of system dynamics was developed in which economic growth and resources are considered from a systemic point of view in order to identify the dependence of economic growth on delayed feedback effects from resource depletion [34]. The model consists of two subsys- tems - renewable natural resources and economies, where the level of resources and GDP are used as accumulators.

G.L. Beklaryan [35] developed a simulation model of the economic development of the Far Eastern Federal District which uses the methods of system dynamics and the agent-based approach. The main idea of the model is to study the influence of a number of factors on the economy of the federal district, such as the growth rate of investment in fixed assets, average wages, subsidies from the federal budget and prices for natural resources. Macroeconomic indicators in the model are described in the notation of system dynamics, and the regions of the federal district are presented as individual agents in one of three states.

Modeling the processes of economic dynamics by industry is presented in [36], where the main modules of the model are public administration, production, consumption, employment, demography, education and the financial system. As the main methods in this study are used agent-based modeling, system dynamics, intersectoral balance models, elements of artificial intelligence and cognitive technologies. The model is based on the determination of the need for various resources (goods, personnel, etc.), gross fixed capital formation and investment demand. In this simulation model, households and legal entities of various forms are represented as agents [37], whose behavior is modeled using special algorithms described in the notation of UML diagrams. System dynamics is used to model the budgets of the state, legal entities and households, as well as to reproduce the dynamics of the population [38].

Another attempt to use system dynamics in the analysis of industries is presented in [39], where a simulation model of the region's supply chain system was developed. The model consists of four main interconnected blocks: population, agriculture, manufacturing and transport. The model made it possible to identify the cyclicality and interdependence of 
the efficiency of the main industries and their influence on each other [40].

Thus, a large number of economic studies use the tools of simulation modeling and, in particular, system dynamics in the analysis of macroeconomic systems. Nevertheless, such models consider either the national economy as a whole or its individual enlarged sectors. Within the framework of this study, an attempt was made to apply the tools of system dynamics to study the model of sustainable development of a separate group of industries, based on a three-sector model of the economy.

\section{Mathematical and algorithmic basis for building a simulation model of the industries' development}

Within the framework of this study, the objects of research are the branches of metallurgy, production of finished metal products, ore mining and mechanical engineering. The choice of the object of research was not made by chance, since it is metallurgy that is one of the leading industries in the Ural macroregion. In accordance with the thesis on the distribution of industries in three sectors, the following are highlighted (in accordance with the classification according to OKVED 2.0):

$\downarrow$ material sector: 07 - Mining of metal ores; 24 - Manufacturing of basic metals;

$\downarrow$ fund-creating sector: 28 - Manufacturing of machinery and equipment not included in other groupings (including: 28.4 - Manufacturing of metal forming machinery and machine tools; 28.91 - Manufacturing of machinery for metallurgy);

$\uparrow$ consumer sector: 25 - Manufacturing of fabricated metal products, except machinery and equipment.

Other industries are not directly considered in this model, but are counted as a kind of "other" industry. The material sector is represented here by the production of objects of labor (iron ores, ores of non-ferrous metals, cast iron, steel, ferroalloys, steel pipes, precious and non-ferrous metals, casting), labor instruments (machinery and equipment) are considered as a fund-creating sector, and consumer goods are consumption (finished metal products). It should be noted here that consumers can be both other sectors of the economy and households. Within the framework of this model, only the metallurgy sector and the industries closest to it are considered.

The technological structure in this model is considered constant, and the output in the industries is set by neoclassical production functions:

$$
X_{i}=A_{i} \cdot K_{i}^{\alpha_{i}} \cdot L_{i}^{\beta_{i}},
$$

where $X_{i}$ - output volume in the $i$-th industry;

$A_{i}$ - coefficient of the neutral technical process in the $i$-th industry;

$K_{i}$ - fixed production assets (hereinafter FA) of the $i$-th industry;

$L_{i}-$ number of people employed in the $i$-th industry;

$\alpha$ - fund elasticity coefficient;

$\beta$ - labor elasticity coefficient;

$i$-industry number $(i=7,24,25,28)$.

The model distinguishes the total number of employees, which changes with a constant growth rate:

$$
\frac{d L}{d t}=\vartheta L
$$

where $L_{i}-$ number of people employed in the $i$-th industry;

$\vartheta$-employment growth rate.

The distribution of workers in industry is presented as a balance ratio:

$$
L=L_{7}+L_{24}+L_{25}+L_{28}+L_{\text {oth }},
$$

where $L_{i}$ - number of people employed in the $i$-th industry; 
$L_{\text {oth }}-$ number of people employed in other industries.

The model makes assumptions about the absence of a lag of capital investments and the constancy of the wear rates of fixed assets. Hence, the change in the FA of the $i$-th industry consists of depreciation and growth due to gross investment:

$$
\frac{d K_{i}}{d t}=-\mu_{i} K_{i}+I_{i},
$$

where $K_{i}-$ FA of $i$-th industry;

$\mu$ - wear factor of FA in the $i$-th industry;

$I_{i}$ - gross investment in the $i$-th industry.

Capital investments in FA of all industries are the purchase of machinery, equipment, buildings, structures, etc. Thus, the output of sectors 28 and 41 together constitutes the total volume of investments that can be invested in different sectors:

$$
X_{28}+X_{41}=I_{7}+I_{24}+I_{25}+I_{28}+I_{o t h},
$$

where $X_{i}$ - the volume of output in the $i$-th industry;

$I_{i}$ - gross investment in the $i$-th industry;

$I_{\text {oth }}$ - gross investment in other industries.

At this stage of the study, sector 41 "Construction of buildings" is not included in the model; therefore, it is considered constant.

Another balance ratio shows the distribution of products of the branches of the material sector (in particular, metallurgy):

$$
X_{24}=a_{0} X_{24}+a_{25} X_{25}+a_{28} X_{28}+a_{\text {oth }} X_{\text {oth }},
$$

where $X_{i}$ - output volume in the $i$-th industry;

$a_{i}$ - coefficients of direct material costs.

Thus, the mathematical model consists of five first-order dynamic elements, three static distribution elements and four non-linear static elements. Endogenous variables are FA and industry outputs. Exogenous variables are the growth rate of the number of employees, the wear rates of the FA of industries, the coefficients of direct material costs, the initial value of the number of employees, the initial distribution of those employed by industries, the initial values of the OPF of industries, and the parameters of production functions. Accordingly, the management in the model is carried out by allocating labor and investment resources.

Relying on equations (1)-(6) and the basic postulates of system dynamics, the author has designed and developed a simulation model for the development of metallurgical and related industries in the AnyLogic software environment. This model is designed in accordance with the following principles:

Dynamic elements are presented in the form of flow diagrams and accumulators, each dynamic element represents a bin, and the flow sets the rate of change of these accumulators.

Non-linear static elements are specified in the form of functional variables, the values of which are calculated based on the values of other variables, parameters and accumulators.

Static distribution elements are specified as parameters, the values of which are adjusted by the user of the model.

Thus, in the developed simulation model, there are five flow diagrams, four of which are almost identical in appearance (Figure 1).

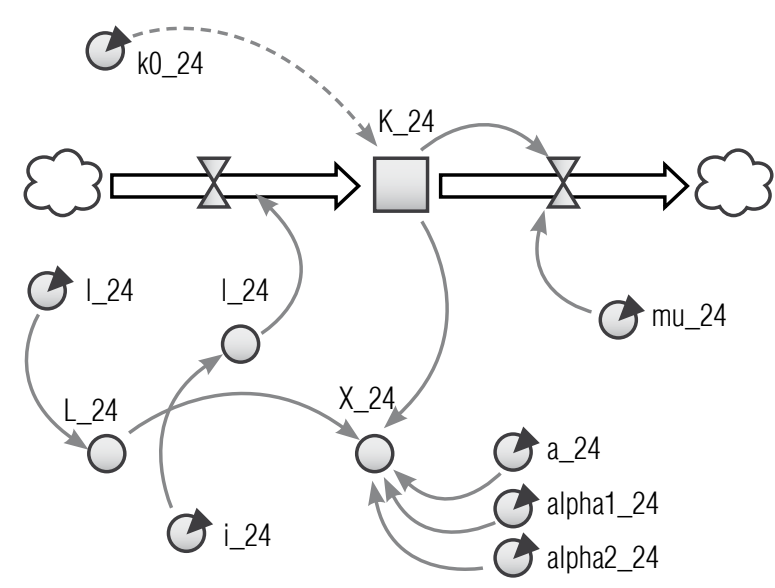

Fig. 1. Flowchart of the metallurgical industry 


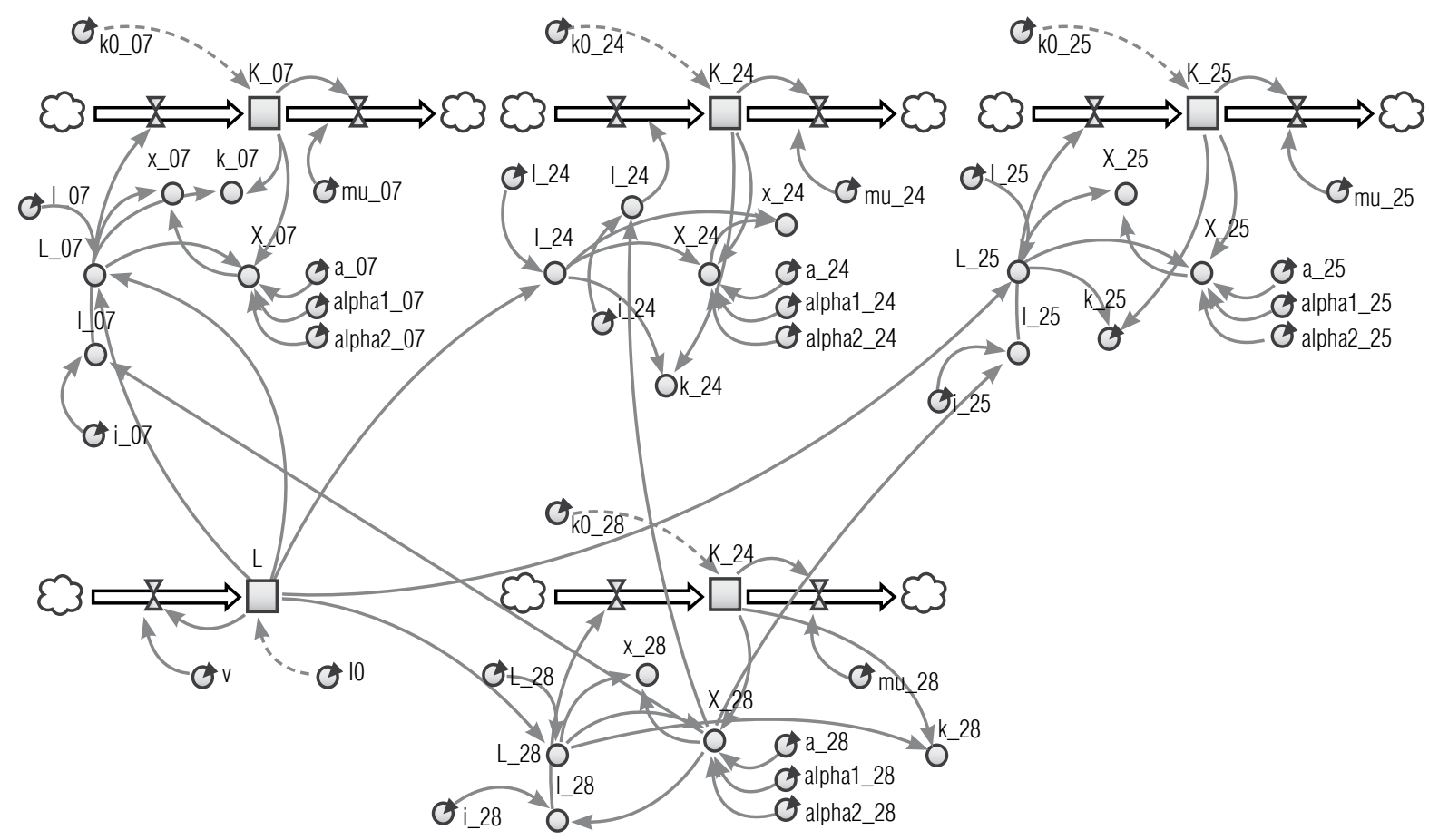

Fig. 2. General view of the simulation model

In general, the simulation model is a set of flow and cause-effect diagrams, where each element is calculated dynamically, in continuous time. The general view of the simulation model is shown in Figure 2.

As accumulators in the model, the volume of fixed assets (capital) of each of the studied industries and the number of those employed in industry are presented, calculated according to the given differential equations (2) and (4) using special elements - flows. Threads set the rate of change of drives per unit of time in a dynamic way, i.e. continuously. With the help of dynamic variables, the output of the industry, as well as the number of employees and the volume of investments, are described (Table 1).

Parameters in the simulation model denote values that are set and changed by the user (not functionally). These are data obtained statistically and empirically, calculated using mathematical and econometric methods, and loaded into the model. The static parameters are mainly the initial values of the storage devices and the coefficients of the production functions ( Table 2).

Thus, the structure of a simulation model for the development of several industries is described, including metallurgy, mining of metal ores, mechanical engineering and the production of finished metal products.

\section{The results of simulation modeling of the development of the metallurgical industry}

To test the model, it is necessary to calculate the values of the exogenous variables (parameters) of the model and set equations (1)-(6) with the corresponding variables. In order to calculate the coefficients $A_{i}, \alpha_{i}$ and $\beta_{i}$, production functions are constructed for each industry. To build production functions, the official 
Endogenous variables of the simulation model

Table 1.

\begin{tabular}{c|c|l} 
Variable name & Variable type & \multicolumn{1}{c}{ Interpretation of the variable } \\
\hline$K \_i$ & Stock & Capital volume of the $\boldsymbol{i}$-th industry \\
\hline$L$ & Stock & Number of people employed in industry \\
\hline flowInvest_i & Flow & Increase in investments in fixed assets of the $i$-th industry \\
\hline flowVyb_i & Flow & Retired fixed assets of the $i$-th industry \\
\hline flow_PrirLabor & Flow & Increase in those employed in industry \\
\hline$X_{-} i$ & Dynamic variable (function) & Gross output of the $i$-th industry \\
\hline$L \_i$ & Dynamic variable & The number of people employed in the $i$-th industry \\
\hline$I \_i$ & Dynamic variable & The volume of investments in the $i$-th industry \\
\hline$x \_i$ & Dynamic variable & Labor productivity of the $i$-th industry \\
\hline$k \_i$ & Dynamic variable & Capital-labor ratio of the $i$-th industry \\
\hline
\end{tabular}

Exogenous model variables

Table 2.

\begin{tabular}{|c|c|c|c|}
\hline $\begin{array}{l}\text { Variable } \\
\text { name }\end{array}$ & $\begin{array}{l}\text { Variable } \\
\text { type }\end{array}$ & Interpretation of the variable & Calculation method \\
\hline$k \_i$ & Parameter & $\begin{array}{l}\text { The initial value of the volume of fixed assets } \\
\text { of the } \boldsymbol{i} \text {-th industry }\end{array}$ & $\begin{array}{l}\text { Taken from statistical sources for } \\
\text { the period preceding the forecast }\end{array}$ \\
\hline$m u \_i$ & Parameter & $\begin{array}{l}\text { The rate of retirement of fixed assets } \\
\text { of the } i \text {-th industry }\end{array}$ & Calculated according to statistical data \\
\hline$l \_i$ & Parameter & $\begin{array}{l}\text { Share of people employed in the } i \text {-th industry in } \\
\text { the total number of people employed in industry }\end{array}$ & Calculated according to statistical data \\
\hline$i \_i$ & Parameter & $\begin{array}{l}\text { The share of investments in fixed assets of the } \\
i \text {-th industry in the total output of mechanical } \\
\text { engineering products }\end{array}$ & Calculated according to statistical data \\
\hline$a \_i$ & Parameter & $\begin{array}{l}\text { Ratio of scientific and technological progress } \\
\text { of the } i \text {-th industry }\end{array}$ & $\begin{array}{l}\text { Calculated by the production function } \\
\text { of the } \boldsymbol{i} \text {-th industry }\end{array}$ \\
\hline alpha1_i & Parameter & Capital elasticity coefficient of the $\boldsymbol{i}$-th industry & $\begin{array}{l}\text { Calculated by the production function } \\
\text { of the } \boldsymbol{i} \text {-th industry }\end{array}$ \\
\hline alpha2_i & Parameter & Labor elasticity coefficient of the $\boldsymbol{i}$-th industry & $\begin{array}{l}\text { Calculated by the production function } \\
\text { of the } \boldsymbol{i} \text {-th industry }\end{array}$ \\
\hline$l \_0$ & Parameter & $\begin{array}{l}\text { The initial value of the number of persons } \\
\text { employed in industry }\end{array}$ & $\begin{array}{l}\text { Taken from statistical sources for } \\
\text { the period preceding the forecast }\end{array}$ \\
\hline$v$ & Parameter & Growth rate of those employed in industry & Calculated according to statistical data \\
\hline
\end{tabular}


data of the Federal State Statistics Service for the period from 2002 to 2018 were used. Unfortunately, it was not possible to use the earlier data due to their incomparability. However, a period of 17 years is quite possible to build a regression model with two explanatory variables at a high level of significance. Values have been recalculated to 2002 comparable prices.

As indicators $X_{i}$, were indicators of the volume of shipped goods of own production for each of the studied industries: mining of metal ores, metallurgical production, production of finished metal products (except for machinery and equipment), production of machinery and equipment not included in other groups.
The $K_{i}$ indicator is calculated as the value of the indicator of fixed assets of commercial organizations for each of the industries. The $L_{i}$ indicator is calculated as the value of the indicator of the average annual number of employees of organizations (Table 3) ${ }^{1}$.

As a result of calculations using the $\mathrm{R}$ programming language and the RStudio package, the following production functions of the studied industries were obtained:

$$
\begin{gathered}
X_{07}=K_{07}^{0.89} \cdot L_{07}^{0.28} \\
X_{24}=0.68 \cdot K_{24}^{0.74} \cdot L_{24}^{0.55} \\
X_{25}=5.9 \cdot K_{25}^{0.38} \cdot L_{25}^{0.49} \\
X_{28}=K_{28}^{0.97} \cdot L_{28}^{0.22} .
\end{gathered}
$$

\section{Descriptive statistics of the initial data for the construction of production functions}

Table 3.

\begin{tabular}{c|c|c|c|c|c|c|c} 
Index & Mean & $\begin{array}{c}\text { Standard } \\
\text { error }\end{array}$ & Median & Minimum & Maximum & Dispersion & $\begin{array}{c}\text { Standard } \\
\text { deviation }\end{array}$ \\
\hline X_07 & 407056.8 & 46944.1 & 988000.0 & 343633.8 & 484446.1 & 2034227172 & 45102.4 \\
\hline X_24 & 1398471.5 & 220461.5 & 2768500 & 1061710 & 1837724.9 & $4.4865 \mathrm{E}+10$ & 211812.6 \\
\hline X_25 & 597651.1 & 91035.0 & 1186500 & 455018.6 & 768581.6 & 7649879809 & 87463.6 \\
\hline X_28 & 529757.8 & 80704.7 & 1125420 & 376389 & 646794.0 & 6012228031 & 77538.6 \\
\hline K_07 & 368006.7 & 85864.8 & 697009 & 274479 & 548720.3 & 6805624929 & 82496.2 \\
\hline K_24 & 708306.6 & 139333.0 & 1320351.5 & 570974.3 & 984168.4 & $1.792 \mathrm{E}+10$ & 133866.8 \\
\hline K_25 & 150132.3 & 29339.2 & 280074.6 & 121115.8 & 210779.5 & 794574579 & 28188.2 \\
\hline K_28 & 171378.7 & 12066.6 & 354314 & 153625.6 & 191204.4 & 134402506 & 11593.2 \\
\hline L_07 & 245.9 & 85.7 & 1090000 & 167 & 357.5 & 6781.9 & 82.4 \\
\hline L_24 & 557.0 & 108.3 & 1076803 & 440.7 & 731.8 & 10822.8 & 104.0 \\
\hline L_25 & 393.7 & 74.4 & 513309 & 292.9 & 487.8 & 5114.5 & 71.5 \\
\hline L_28 & 742.0 & 313.2 & 13.1 & 299.4 & 1205.0 & 90548.1 & 300.9 \\
\hline
\end{tabular}

\footnotetext{
1 To calculate the indicators, the following statistical collections were used: "Industrial production in Russia - 2019", "Industrial production in Russia - 2016", "Industrial production in Russia - 2010", "Industrial production in Russia - 2002"

2 Indicators $X_{i}$ and $K_{i}$ are calculated in millions of rubles, indicators $L_{i}-$ in thousands of people
} 
It should be noted here that the sum of the coefficients of elasticity for funds and labor is greater than one, which indicates the presence of increasing returns. This thesis is based on the results of the research by S.V. Orekhova and E.V. Kislitsyn [41] devoted to the analysis of the aggregate productivity of factors, which is understood as the unexplained remainder of the growth of the final product. In particular, the study proved the presence of the aggregate productivity of factors in the heavy industry sectors, including metallurgy, which suggests the presence of increasing returns.

All constructed functions and their coefficients are statistically significant at the level of $5 \%$, the coefficients of determination range from 0.4 for metallurgy to 0.99 for mechanical engineering. The values of all exogenous variables (parameters) described in Table 2 are calculated and presented in Table $4 .^{3}$

The main idea of simulation models is to simulate various situations that arise in the system, i.e. simulate scenarios. Within the framework of this work, six different scenarios for the development of metallurgy and related industries were investigated. The first scenario is the development of the economic system without significant changes in accordance with the given production functions. In this scenario, it is assumed that all the parameters of the model are constants (i.e., all the growth rates of the main indicators are preserved). This scenario reflects the existing picture and allows us to predict the development of the economies of various industries. Labor productivity, capital-labor ratio (Figure 3) and gross output (Figure 4) are identified as the analyzed variables.

\section{Model parameter values as of 2018}

Table 4.

\begin{tabular}{c|c|c|c|c}
$\begin{array}{c}\text { Variable } \\
\text { name / } \\
\text { Industry }\end{array}$ & $\begin{array}{c}07- \\
\text { Mining } \\
\text { of metal } \\
\text { ores }\end{array}$ & $\begin{array}{c}\text { Manufacture } \\
\text { of basic } \\
\text { metals }\end{array}$ & $\begin{array}{c}25 \text { - Manufacture } \\
\text { of fabricated metal } \\
\text { products, except } \\
\text { machinery and equipment }\end{array}$ & $\begin{array}{c}28-\text { Manufacture } \\
\text { of machinery and equipment } \\
\text { not included in other } \\
\text { groupings }\end{array}$ \\
\hline$k \_i$ & 1709200 & 3255000 & 699600 & 509900 \\
\hline$m u \_i$ & 0.013 & 0.009 & 0.007 & 0.011 \\
\hline$l i i$ & 0.032127 & 0.043398 & 0.04877 & 0.039027 \\
\hline$i \_i$ & 0.207959 & 0.250129 & 0.06384 & 0.033877 \\
\hline$a \_i$ & 1 & 0.68 & 5.9 & 0.97 \\
\hline alpha1_i & 0.89 & 0.74 & 0.38 & 0.22 \\
\hline alpha2_i & 0.28 & 0.55 & 0.49 & \\
\hline$l \_0$ & & & 9887.1 & \\
\hline$v$ & & & -0.00036 & \\
\hline
\end{tabular}

3 To calculate the indicators, the following statistical collections were used: "Industrial production in Russia - 2019", "Industrial production in Russia - 2016" and the database "SPARK-Interface" 


\section{Mining of metal ores}

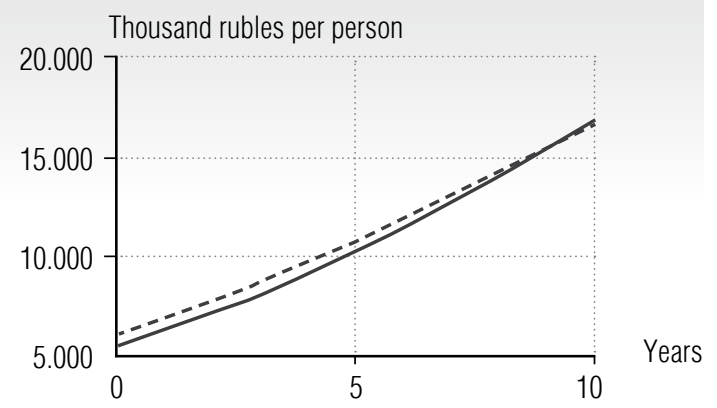

\section{Manufacturing of fabricated metal products}

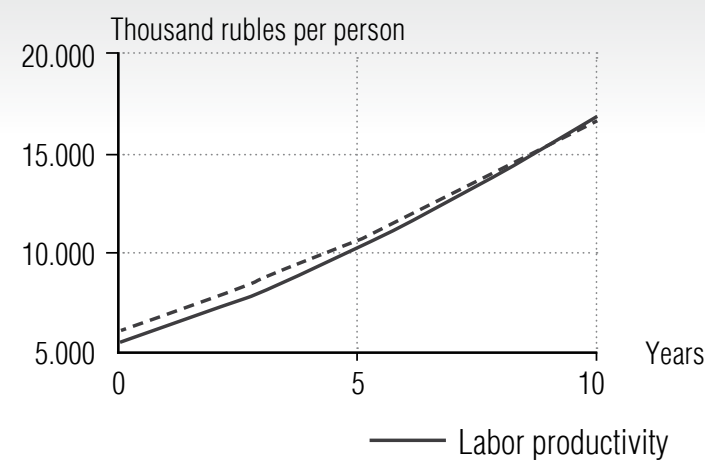

\section{Metallurgy}

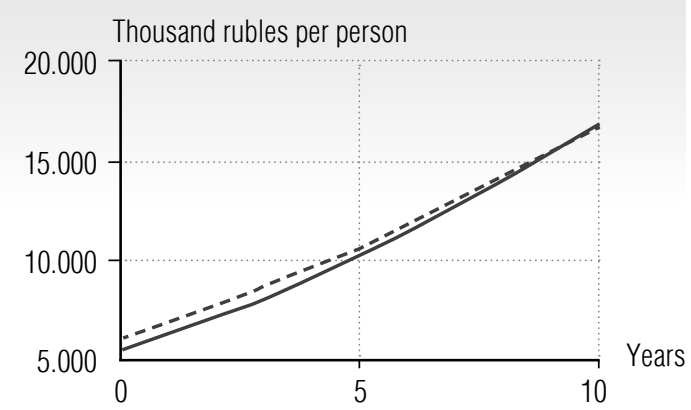

Mechanical engineering

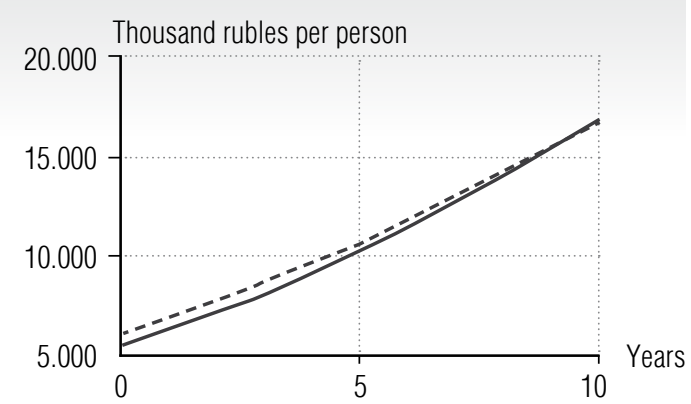

----- Capital-labor ratio

Fig. 3. Dynamics of changes in labor productivity and capital-labor ratio according to the scenario no 1

\section{Mining of metal ores}

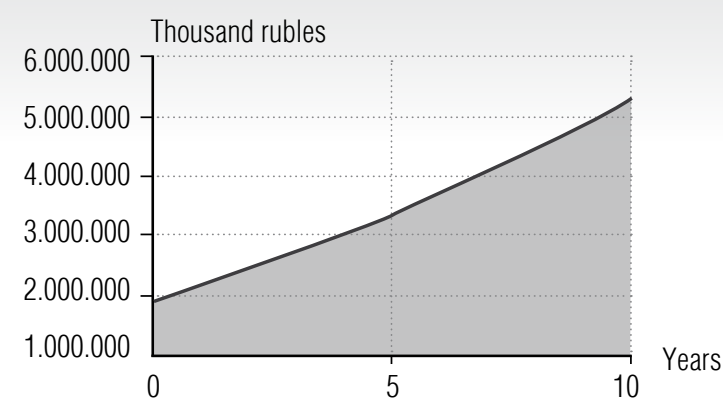

\section{Manufacturing of fabricated metal products}

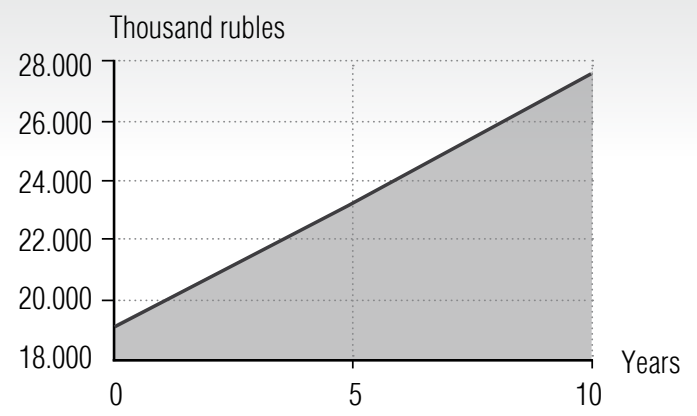

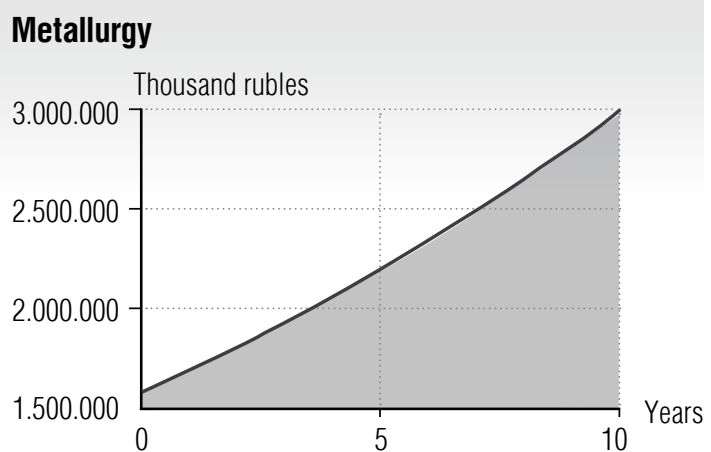

Mechanical engineering

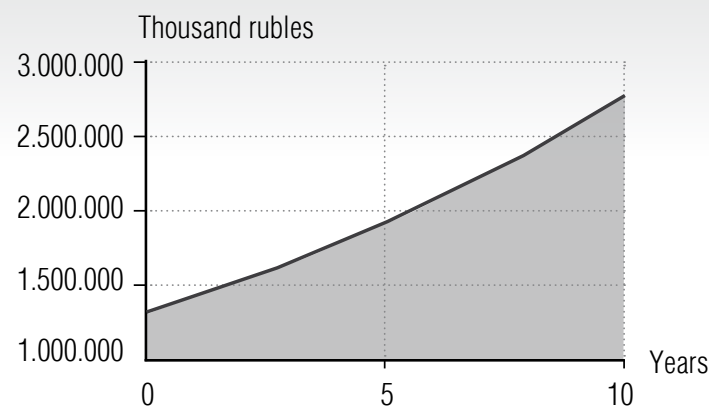

Fig. 4. Dynamics of changes in gross output according to scenario no 1 
It should be noted right away that the total volumes of output in some industries may not reflect the actual values at the beginning of the analyzed period, since, firstly, production functions were based on prices in 2002 and, secondly, the initial value of output was not specified in this model. The main goal here is to track the growth rates of individual industries.

So, with the existing growth rate of the number of workers in industry (and as of 2018 this rate was $-0.36 \%$ per year) and the growth rate of capital investment in fixed assets, the capital-labor ratio of all studied industries gradually reaches the level of labor productivity in 10 years. With constant indicators, the growth in output in the mining industry of metal ores will grow 2.78 times, metallurgy -1.9 times, production of finished metal products -1.44 times, and mechanical engineering -1.95 times over 10 years.
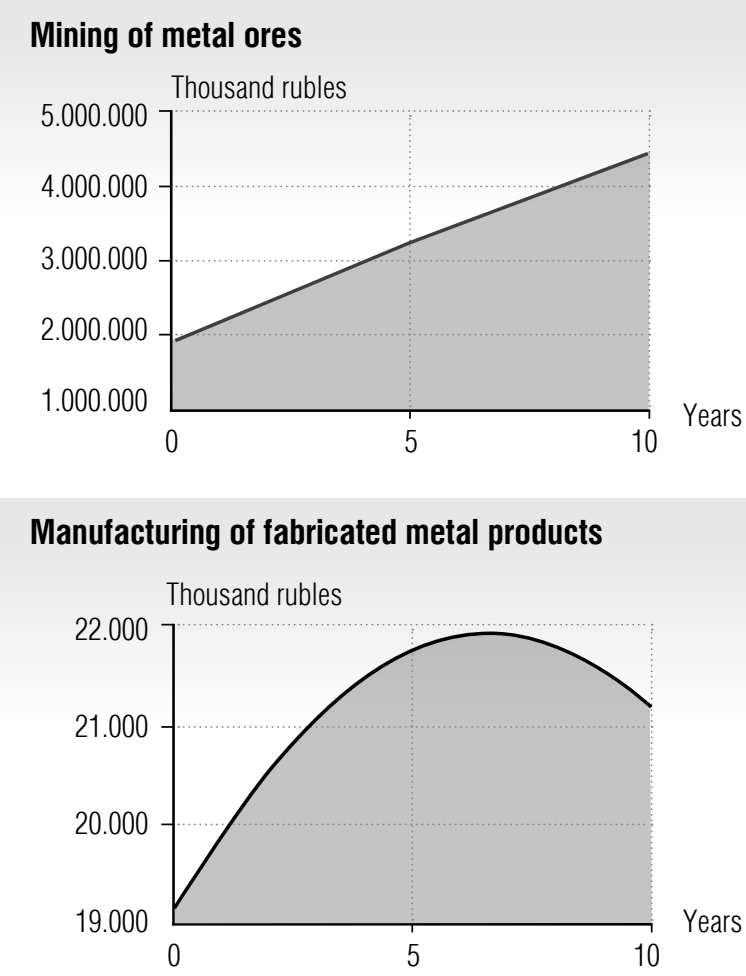

Next, three pessimistic and two optimistic scenarios are analyzed. The second scenario is a reflection of the already existing trend towards a reduction in the number of workers in industry. The simulation model specifies a reduction in the growth rate of the number of workers in industry by $1 \%$ per year (Figure 5).

First of all, the reduction in the inflow of new labor into industry as a whole will affect the industries in which labor productivity affects output to a greater extent than the capitallabor ratio. According to the calculated values, output in the metallurgy industry will gradually slow down and practically stop in the ninth year. In the production of finished metal products, the situation is even more negative already in the sixth year, production volumes will begin to decline. The metal ore mining and mechanical engineering industries will not suffer so much, though their production growth rates will also decline.
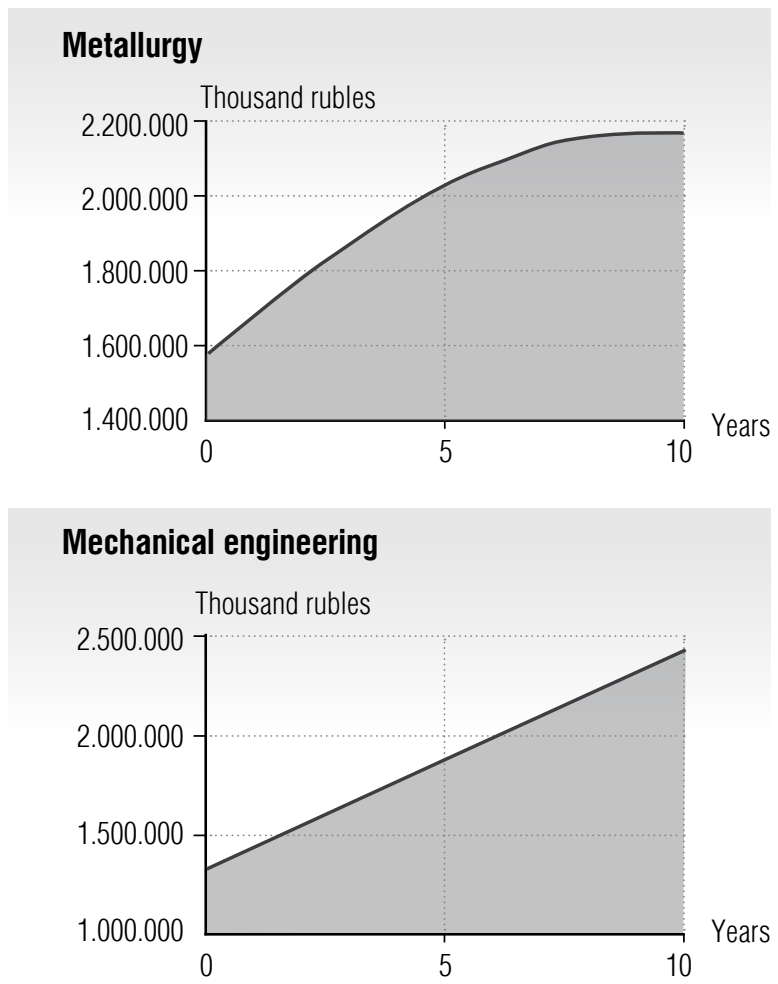

Fig. 5. Dynamics of changes in gross output according to scenario no 2 


\section{Mining of metal ores}

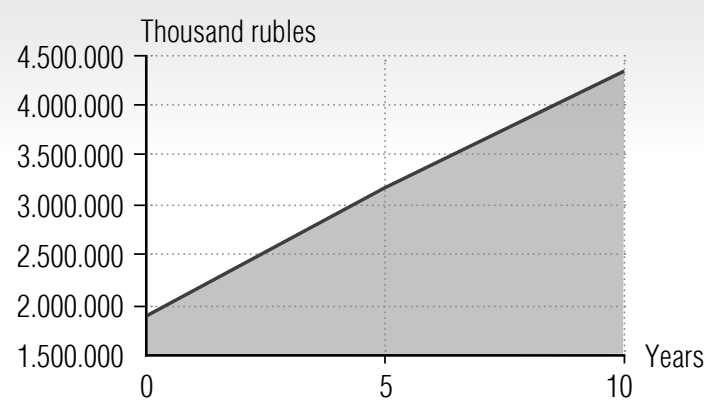

\section{Manufacturing of fabricated metal products}

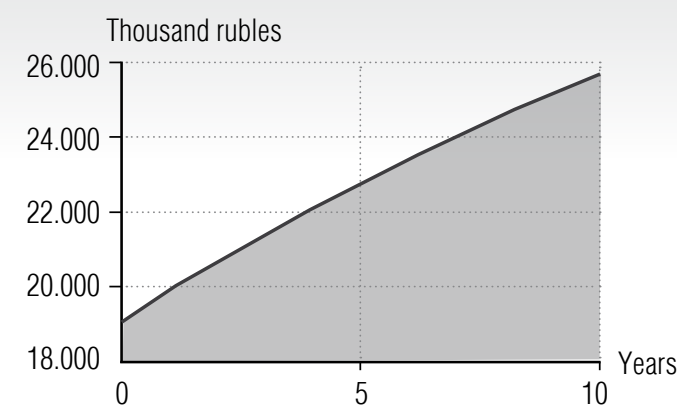

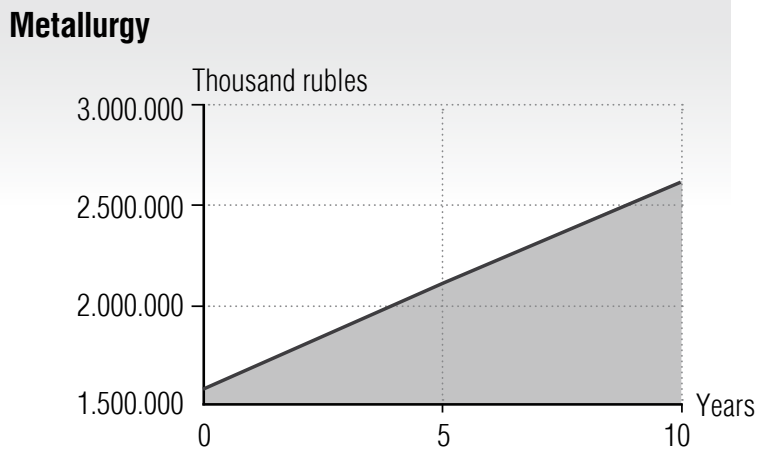

Mechanical engineering

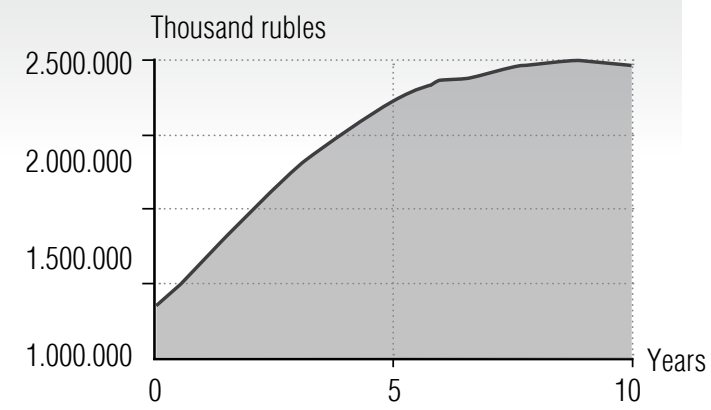

Fig. 6. Dynamics of changes in gross output according to scenario no 3

\section{Mining of metal ores}

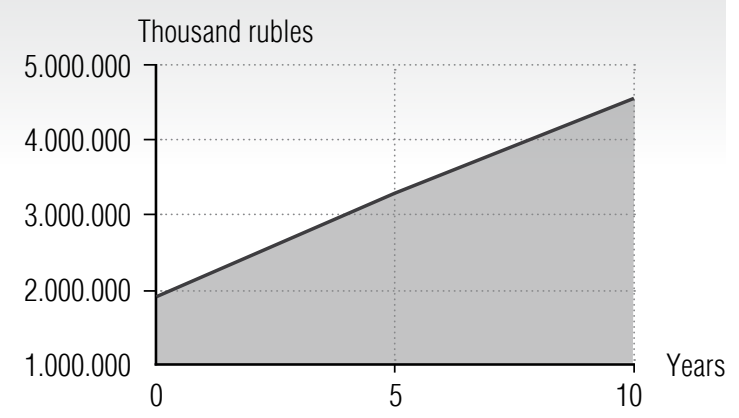

\section{Manufacturing of fabricated metal products}

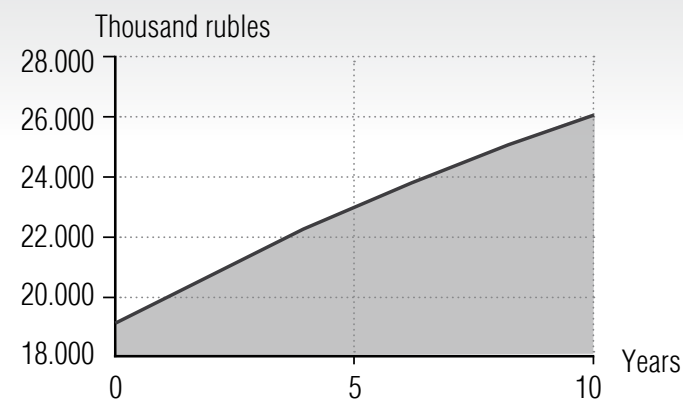

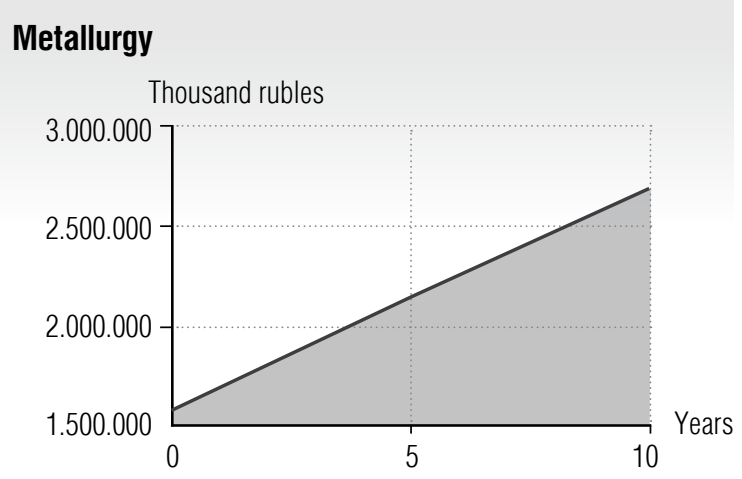

\section{Mechanical engineering}

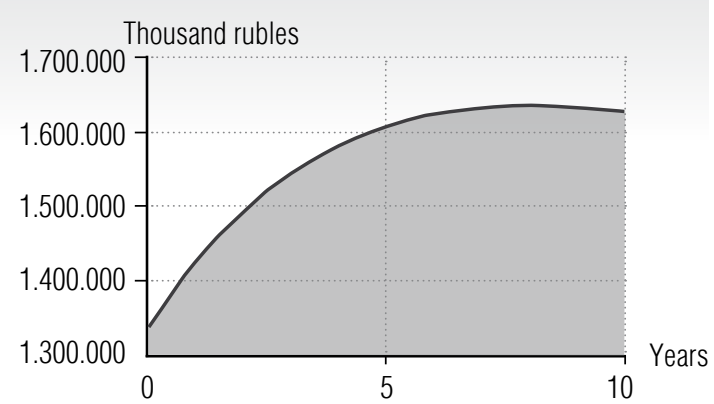

Fig. 7. Dynamics of changes in gross output according to scenario no 4 
The third scenario is a reduction in the share of workers in the engineering industry in the total number of industrial workers by $25 \%$ per year. This scenario is an attempt to trace the causal relationship between the output of industries and the production of fixed assets (Figure 6).

It is easy to see that the rate of output of the machine-building industry has been slowing down quite clearly since the third year, while with a general decrease in the number of employees in all industries, such a trend was not observed. In addition, similar indicators in other industries are also declining. Thus, the growth rate of output in the metal ore mining industry will be only 2.28 , metallurgy -1.27 , and in the production of finished metal products -1.34 over 10 years, which is significantly lower than in scenario no 1 .

The next scenario is a reduction in the share of investments in the mechanical engineering industry by $25 \%$ per year (Figure 7 ) in the total volume of investments in industrial production.

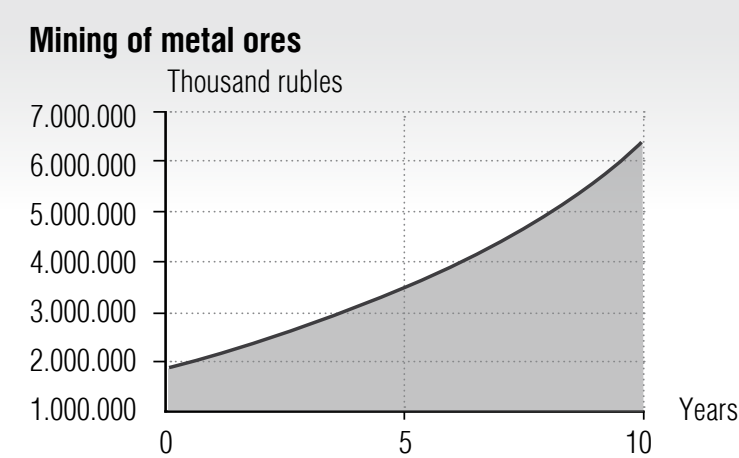

\section{Manufacturing of fabricated metal products}

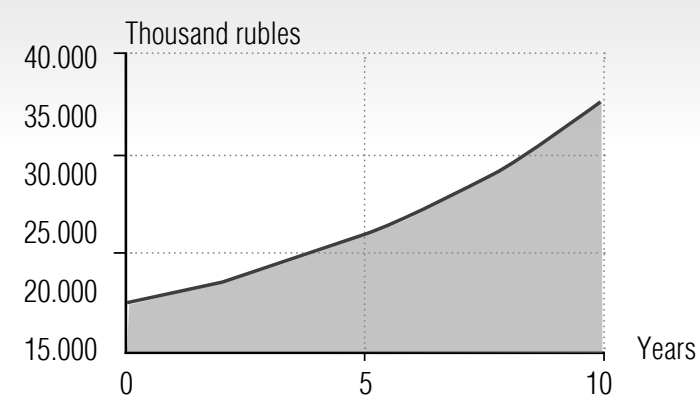

As expected, there should be a trend similar to the third scenario. Nevertheless, while maintaining the general trends, there is still a quantitative difference with the previous scenario.

The output of the machine-building industry suffers more: its rates begin to decline already in the eighth year of the forecast. However, the output rates of other industries are falling more slowly. Here, the balance equation (5) affects, i.e. investments in other sectors remain the same. Even when the pace of production in the mechanical engineering industry begins to fall, other industries feel it less, which is very unusual. It turns out that the industries under study compensate the inflow of investments from other industries (for example, construction) to a greater extent than the outflow of workers from the engineering industry.

The fifth scenario is optimistic - an increase in the growth in the number of workers in industry while maintaining their distribution by industry by $1 \%$ per year (Figure 8 ).
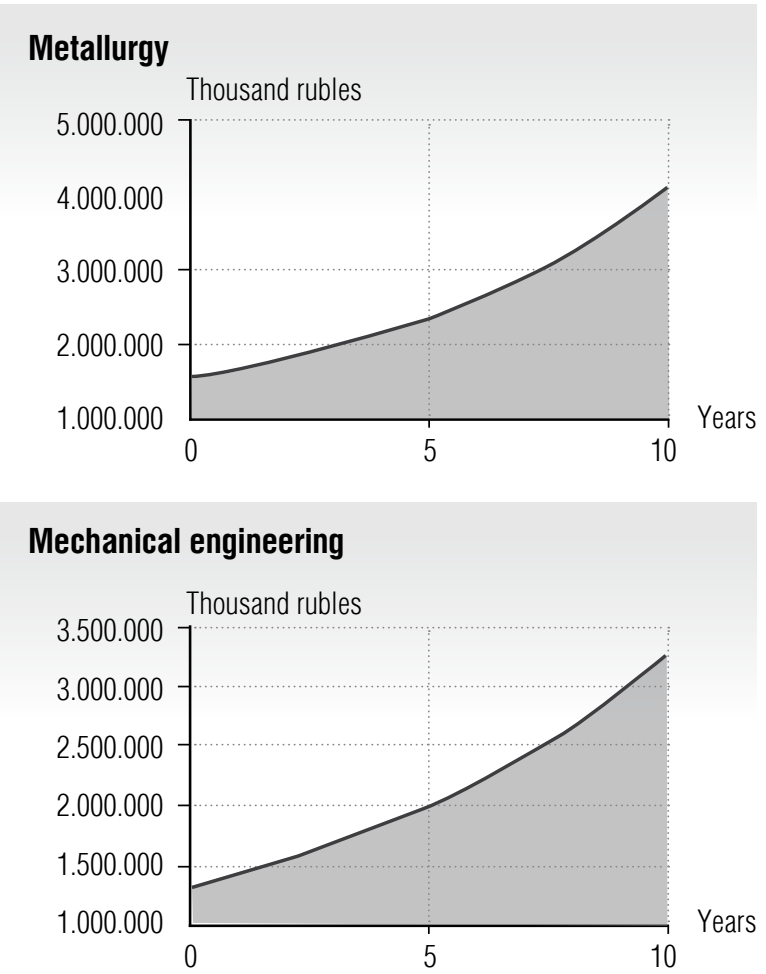

Fig. 8. Dynamics of changes in gross output according to scenario no 5 
The increase in the number of employees has a positive effect on the growth rate of products in all sectors. Moreover, a feedback loop is actively starting to work, which links the output of fund-forming industries (in particular, mechanical engineering) with capital gains in other industries. Thus, the further we build our forecast, the greater the share in the increase in production output is taken by the increase in capital investments in fixed assets. This effect is called a self-replicating feedback loop.

The last scenario in this study is devoted to the analysis of the development of industries with an increase in the share of investments in the mechanical engineering industry by $10 \%$ per year (Figure 9).

Naturally, in this scenario, there is also an increase in the growth rates of output in all sectors in comparison with the standard scenario no 1 . However, it should be noted

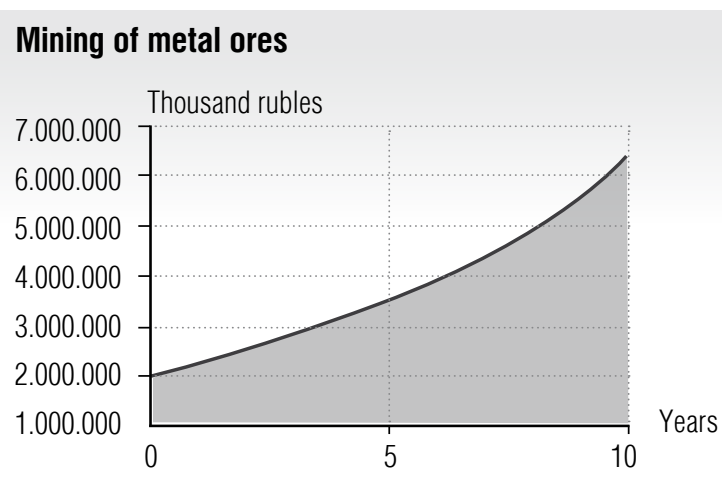

Manufacturing of fabricated metal products

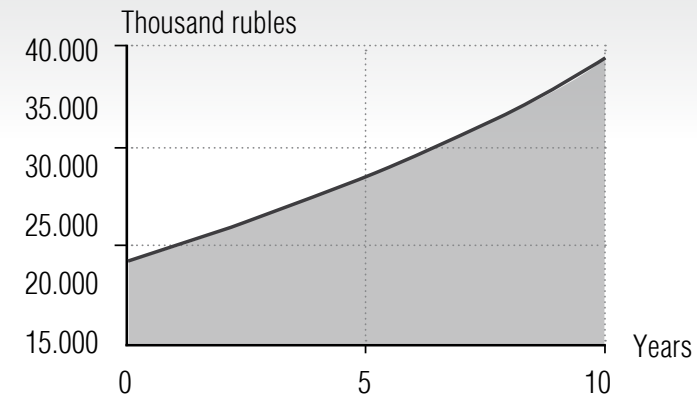

that, first of all, the output in the machinebuilding industry is greatly increasing - by 3.7 times over 10 years. However, in the metallurgical industries the acceleration of growth rates is slower in comparison with the scenario №5. It should be noted here that, firstly, the increase in labor resources as a whole increases the growth to a greater extent linearly and, secondly, the increase in investment in one industry according to the balance equation (5) implies their outflow (albeit small) from other industries. However, the exponential growth of the mechanical engineering industry in the longer term will entail similar growth in the metallurgical industries, which will subsequently exceed the growth rate in scenario 5. However, the developed simulation model cannot build sufficiently plausible forecasts for a period exceeding 10 years.
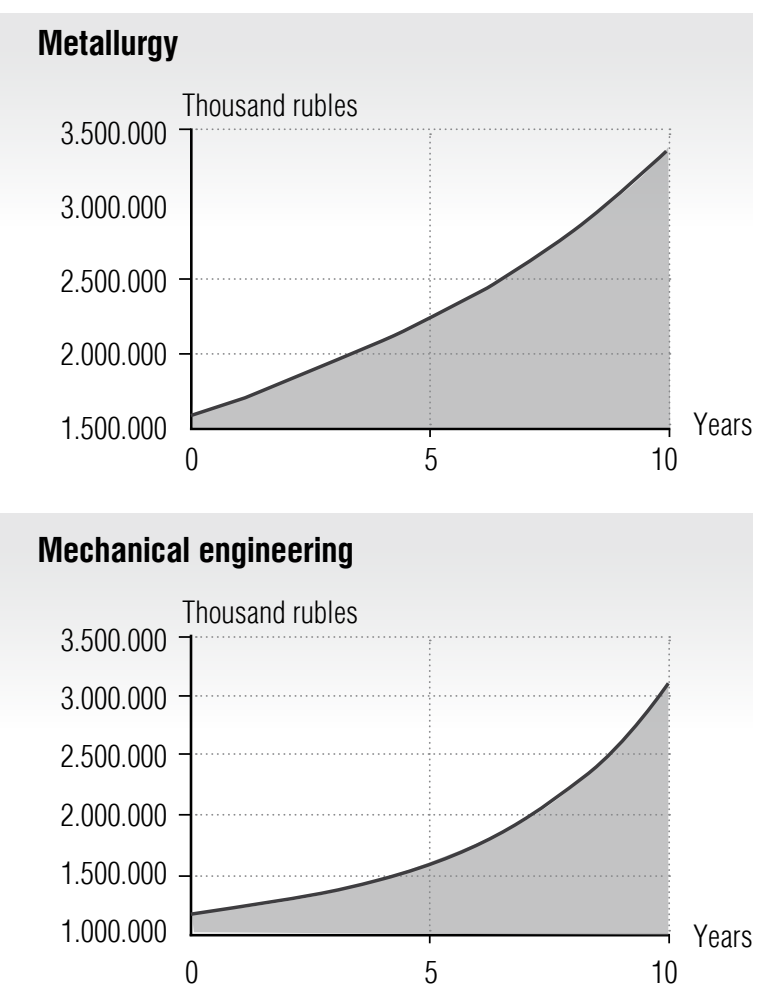

Fig. 9. Dynamics of changes in gross output according to scenario no 6 
Thus, the possibility of using the developed simulation model for analyzing and forecasting the development of metallurgy and related industries has been demonstrated. Naturally, this set of scenarios is conditional. Nevertheless, the simulation model allows us to add new scenarios in accordance with the industrial policy of the Russian Federation.

\section{Conclusion}

In the course of this study, the following results were obtained.

Analysis of scientific works devoted to the construction of simulation models of economic systems showed that research in this area is extremely relevant, and their number is increasing every year. However, the use of system dynamics is mainly limited to studies of either the national economic system as a whole, or individual regions. Moreover, the development of individual industries also needs to be investigated with modern tools.

The three-sector model of the economy of V.A. Kolemaev, where the sectors are not the global sectors of the national economy but individual industries: within the framework of this work, these are metallurgy, iron ore mining, mechanical engineering and the production of finished metal products is modified. Five dynamic equations of the first order, three balance equations and four nonlinear functions are created, which together allow us to analyze, predict and optimize the sustainable development of individual industries.

On the basis of the analytical model of metallurgical industries, a simulation model of the development of individual industries in the notation of system dynamics has been developed. The accumulators (fixed production assets of each industry and the number of workers in the industry), changing their flows, as well as dynamic variables and model parameters are determined. The simulation model so constructed is a complex of flow causal diagrams that reflect not only the structure of the economic system under study, but also its behavior over several periods of time.

The constructed simulation model was tested taking into account the available data for 2002-2018. Production functions are constructed and all exogenous variables of the model are empirically calculated. To demonstrate the work of the simulation model, six scenarios for the development of the economic system under study were proposed standard, three pessimistic and two optimistic. Scenario analysis showed the main points of management of the model and, as a consequence, the entire economic system being studied. The results of this study can be applied, first of all, by public authorities to adjust industrial policy.

\section{References}

1. Orekhova S.V. (2017) Resources and sustainable growth of an industrial metallurgical enterprise: an empirical assessment. Modern Competition, vol. 11, no 3, pp. 65-76 (in Russian).

2. Tretyakova E.A. (2013) Evolution of research and evaluation methodology of sustainable development of social and economic systems. World Applied Sciences Journal, vol. 25, no 5, pp. 756-759. DOI: 10.5829/idosi.wasj.2013.25.05.13335.

3. Orekhova S.V. (2017) Assessment of the economic growth stability of the metallurgical complex. Vestnik NGUEU, no 2, pp. 204-220 (in Russian).

4. Baranenko S.P., Dudin M.N., Lyasnikov N.V., Busygin K.D. (2014) Use of environmental approach to innovation-oriented development of industrial enterprises. American Journal of Applied Sciences, vol. 11, no 2, pp. 189-194. DOI: 10.3844/ajassp.2014.189.194. 
5. Rudenko L.G., Zaitseva N.A., Larionova A.A., Chudnovsky A.D., Vinogradova M.V. (2015) Socio-economic role of service-sector small business in sustainable development of the Russian economy. European Research Studies Journal, vol. 18, no 3, pp. 219-234. DOI: 10.35808/ersj/468.

6. Dubrovsky V., Yaroshevich N., Kuzmin E. (2016) Transactional approach in assessment of operational performance of companies in transport infrastructure. Journal of Industrial Engineering and Management, vol. 9, no 2, pp. 389-412.

7. Orekhova S.V., Kislitsyn E.V. (2019) Small business and structural changes in industry. Terra Economicus, vol. 17, no 4, pp. 129-147 (in Russian). DOI: 10.23683/2073-6606-2019-17-4-129-147.

8. Demidova O.A., Ivanov D.S. (2016) Models of economic growth with heterogeneous spatial effects (on the example of Russian regions). HSE Economic Journal, vol. 20, no 1, pp. 52-75.

9. Surnina N.M., Ilyuhin A.A., Ilyuhina S.V. (2017) Demographic landscape of the region: factors, dynamics, trends, forecasts. Journal of the Ural State University of Economics, no 4, pp. 32-44 (in Russian). DOI: 10.29141/2073-1019-2017-16-4-3.

10. Barkhatov V.I., Benz D.S. (2019) Industrial markets of the Ural region: Economic growth under "new normal". Upravlenets - The Manager, vol. 10, no 3, pp. 83-93 (in Russian).

DOI: $10.29141 / 2218-5003-2019-10-3-8$.

11. Kulkov V.M., Kaimanakov S.V., Tenyakov I.M. (2014) The economic growth in Russia: national model, quality and security. National Interests: Priorities and Security, vol. 10, no 38, pp. 9-19 (in Russian).

12. Forrester J.W. (1969) Urban dynamics. Waltham, MA: Pegasus Communications.

13. Forrester J.W. (1958) Industrial dynamics: A major breakthrough for decision makers. Harvard Business Review, vol. 36, no 4, pp. 37-66.

14. Meadows D.H. (1972) Limits to growth: A report for the Club of Rome's project on the predicament of mankind. N.Y.: Universe Books.

15. Meadows D.H., Randers J., Meadows D.L. (2005) Limits to growth: The 30 year update. London: Earthscan.

16. Sidorenko V.N. (1998) System dynamics. Moscow: TEIS (in Russian).

17. Akopov A.S. (2006) System-dynamic approach to managing the investment activity of an oil company. Audit and Financial Analysis, no 2, pp. 165-200 (in Russian).

18. Akopov A.S. (2012) Designing of integrated system-dynamics models for an oil company. International Journal of Computer Applications in Technology, vol. 45, no 4, pp. 220-230. DOI: 10.1504/IJCAT.2012.051122.

19. Akopov A.S., Khachatryan N.K. (2014) System dynamics. Moscow: CEMI (in Russian).

20. Solow R.M. (1956) Contribution to the theory of economic growth. Quarterly Journal of Economics, vol. 70, no 1, pp. 65-94. DOI: 10.2307/1884513.

21. Intriligator M. (1971) Mathematical optimization and economic theory. N.Y.: Prentice-Hall.

22. Kolemaev V.A. (2005) Mathematical economics. Moscow: UNITY-DANA (in Russian).

23. Kolemaev V.A. (2008) Optimal balanced growth of the open three-sector economy. Applied Econometrics, vol. 11, no 3, pp. 15-42 (in Russian).

24. Trofimova V.Sh., Ozerova K.A. (2017) Economic and mathematical modeling of macroeconomic dynamics. Mathematics and Computer Modeling in Economics, Insurance and Risk Management, no 2, pp. 85-89 (in Russian).

25. Kislitsyn E.V. (2017) Principles of building a simulation model of a market with limited competition (for example, the market of mobile operators in Yekaterinburg). Transbaikal State University Journal (Bulletin of ZabGU), vol. 23, no 10, pp. 101-110 (in Russian). DOI: 10.21209/2227-9245-2017-23-10-101-110. 
26. Borshchev A., Karpov Y., Kharitonov V. (2002) Distributed simulation of hybrid systems with AnyLogic and HLA. Future Generation Computer Systems, vol. 18, no 6, pp. 829-839. DOI: $10.1016 / \mathrm{S} 0167-739 \mathrm{X}(02) 00055-9$.

27. Bocharov E.P., Aleksenceva O.N., Ermoshin D.V. (2008) Assessment of risks of industrial enterprises on the basis of simulation modeling. Applied Informatics, no 1, pp. 15-24 (in Russian).

28. Kislitsyn E.V. (2018) Simulation of the process of crediting individuals using a credit rating. Proceedings of Voronezh State University. Series: Economics and Management, no 3, pp. 112-118 (in Russian).

29. Vorontsovskiy A.V. (2010) Modern approaches to modeling of the economic growth. St. Petersburg University Journal of Economic Studies, no 3, pp. 105-119 (in Russian).

30. Shults D.N., Yakupova I.N. (2016) Agent-based modeling of the influence of microstructure on economic properties. Russian Journal of Economic Theory, no 1, pp. 70-81 (in Russian).

31. Yandybaeva N.V., Kushnikov V.A. (2014) Mathematical model for forecasting of indicators of economic safety of the Russian Federation. Vestnik of Astrakhan State Technical University. Series: Management, Computer Sciences and Informatics, no 3, pp. 93-101 (in Russian).

32. Piskun E.I. (2014) The evaluation of effectiveness of the implementation of the strategy of innovative development of industrial and economic systems. Science Journal of VolSU. Global Economic System, no 5, pp. 55-68 (in Russian). DOI: 10.15688/jvolsu3.2014.5.6.

33. Mathur M., Agarwal S. (2015) Sustainability dynamics of resource use and economic growth. A discussion on sustaining the dynamic linkages between renewable natural resources and the economic system. Discussion paper. Available at: http://www.teriin.org/policybrief/files/aug15/files/downloads/Discussion_paper_ Sustainability_Aug2015.pdf (accessed 15 December 2020).

34. Mathur M., Agarwal S. (2015) Dynamics of sustainable interaction between resource consumption and economic growth. Karelian Scientific Journal, no 4, pp. 48-59 (in Russian).

35. Beklaryan G.L. (2018) Decision support system for sustainable economic development of the Far Eastern Federal District. Business Informatics, no 1, pp. 66-75.

DOI: $10.17323 / 1998-0663.2018 .4 .66 .75$.

36. Mashkova A.L., Savina O.A., Mamatov A.V., Novikova E.V. (2018) Computer modeling of sectoral economic dynamics. Proceedings of the Southwest State University, vol. 22, no 5, pp. 96-108 (in Russian). DOI: 10.21869/2223-1560-2018-22-5-96-108.

37. Mashkova A.L. (2016) Forecasting long-term development of macroeconomic systems based on agent modeling. Public Administration. E-Journal, no 57, pp. 49-68 (in Russian).

38. Novikova E.V., Mashkova A.L. (2018) Creation of the initial generation of agents in the computer model of industrial development of the Russian economy. Proceedings of the VII International Scientific and Technical Conference "Information Technologies in Science, Education and Manufacturing", Belgorod, Russia, 17-19 October 2018, pp. 313-318 (in Russian).

39. Molodetskaya E.Yu. (2017) Simulation of supply chain systems at the macroeconomic level as a tool for managing the economic development of the region. Economics: Yesterday, Today and Tomorrow, vol. 7, no 9A, pp. 180-191 (in Russian).

40. Lychkina N., Molodetskaya E., Morozova Yu. (2017) The simulation model of supply chains on the macroeconomic level is the tool to control the economic development of the region. Strategic Innovative Marketing. Springer, pp. 357-362. DOI: 10.1007/978-3-319-56288-9_47.

41. Orekhova S.V., Kislitsyn E.V. (2019) Total factor productivity in the Russian industry: Small vs large enterprises. Journal of New Economy, vol. 20, no 2, pp. 127-144.

DOI: $10.29141 / 2073-1019-2019-20-2-8$. 


\section{About the authors}

\section{Evgeniy V. Kislitsyn}

Cand. Sci. (Econ.);

Head of Information Technology and Statistics Department, Ural State University of Economics, 62, 8 Marta Street, Yekaterinburg 620144, Russia;

E-mail: kev@usue.ru

ORCID: 0000-0003-1518-0043

\section{Victor V. Gorodnichev}

Senior Lecturer, Information Technology and Statistics Department, Ural State University of Economics, 62, 8 Marta Street, Yekaterinburg 620144, Russia;

E-mail: helltoaster@yandex.ru 